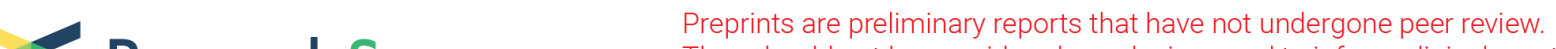 $\begin{array}{ll}\text { Research Square } & \text { They should not be considered conclusive, used to inform clinical practice, } \\ \text { or referenced by the media as validated information. }\end{array}$
}

\section{Chromosome Karyotype and Stability Identification of New Synthetic Hexaploid Wheat}

\section{Yajuan Wang}

College of Agronomy, Northwest A \& F University

\section{Siwen Wang}

College of Agronomy, Northwest A \& F University

\section{Xiujuan Jia}

College of Agronomy, Northwest A \& F University

\section{Zengrong Tian}

College of Agronomy, Northwest A \& F University

\section{Yongfu Wang}

College of Agronomy, Northwest A \& F University

\section{Changyou Wang}

College of Agronomy, Northwest A \& F University

Hong Zhang

College of Agronomy, Northwest A \& F University

\section{Xinlun Liu}

College of Agronomy, Northwest A \& F University

Jixin Zhao

College of Agronomy, Northwest A \& F University

\section{Pingchuan Deng}

College of Agronomy, Northwest A \& F University

Ji Wanquan ( $\square$ jiwanquan2008@126.com )

College of Agronomy, Northwest A \& F University https://orcid.org/0000-0003-0663-4568

\section{Research Article}

Keywords: Synthetic hexaploid wheat, Chromosome karyotype, FISH, Mc-GISH, Resistance to stripe rust

Posted Date: February 24th, 2021

DOl: https://doi.org/10.21203/rs.3.rs-229489/v1

License: (c) (i) This work is licensed under a Creative Commons Attribution 4.0 International License. Read Full License 


\section{Abstract}

Synthetic hexaploid wheats offer breeder ready access to potentially novel genetic variations in wild ancestral species. In present study, we used MY3478 $(2 n=4 x=28, A A B B)$ as female crossing with SY41 $(2 n=2 x=14, D D)$ of stripe rust resistant as male through natural chromosome doubling to constructed the new hexaploid wheat line NA0928. Agronomic traits and cytological analysis were characterized in NA0928 of S8-S9 generations. The major study and results were described as follows, agronomic character variation coefficient in NA0928 of S8 generation showed that the effective tiller number $(55.3 \%)>$ spike length $(15.3 \%)>$ number of spikelets $(13.9 \%)>$ plant height $(8.7)$. It is suggested that the effective tiller number and spike length have great utilization value in breeding. Cytological observation and fluorescence in situ hybridization (FISH) results showed that the chromosome number and configuration have rich variations in S9 of NA0928. Chromosome number variation range of 36-44. Numerous chromosome karyotype variations were almost detected in A and B subgenomes. In addition, more diverse types of chromosomal structure variations were observed in the stripe rust resistant strains with more excellent performance than susceptible strains in agronomic traits. Especially, the tillering number of the resistant strains were much higher. Here, Meiosis stage of pollen mother cells and multicolor-GISH (Mc-GISH) results showed that two new synthetic hexaploid wheat lines were obtained, which showed genetic stability, one line was resistance to stripe rust, and the other one line was susceptible stripe rust, at the same time, there had two excellent characteristics with high 1000-grain weight and multiple tillers. They will be valuable germplasm materials in wheat breeding utilization.

\section{Introduction}

Owing to extensively using of the excellent parents for directional selection in wheat breeding programs, the genetic basis of cultivars has been more and more narrow and the genetic diversity degree has been lost (Brenchley et al. 2012), Many studies have shown that the narrow genetic not only limits improvement of crop yield and quality, but also increases the vulnerability of crops to biological and nonbiological environmental stresses, narrow genetic basis has become the "neck flask" which is difficult to make breakthrough in wheat breeding (Prasad et al. 2000; Fedak et al. 2000). Synthetic wheat can transfer the genetic material of tetraploid wheat and Aegilops tauschii and obtain a permanent "bridge" resource with two chromosomes at the same time. This method can overcome the problem of "evolution bottleneck" of wheat. Based on this "bridge" material, it can be used for genetic evaluation and breeding improvement (Lange et al. 1992a; Lange et al. 1992b). For example, Lange and Jochemsen reported that synthetic hexaploid wheat crossed between Triticum turgidum and Aegilops tauschii containing the same genetic constitution as common wheat (AABBDD, $2 n=42$ ), it is feasible to transfer the good genes of the two wild relatives into common wheat. Currently several disease-resistant and insect-resistant genes were discovered in synthetic wheat lines originating from the donor species of wheat, Previous studies suggested Ae. tauschii contained stripe rust and stem rust genes (Singh et al. 2000; Assefa et al. 2004), powdery mildew resistance genes (Miranda et al. 2007; Wiersma et al. 2017), leaf blight c resistance genes (Simo'n et al. 2001), other pest-resistant genes, etc (Lage et al. 2003). Some research revealed that 
tetraploid wheat also carried powdery mildew genes (Mohler et al. 2013; He et al. 2020), stripe rustgenes (Xiang et al. 2016), Russian wheat aphid (Lage et al. 2000) and English grain aphid (Liu et al. 2012) resistance genes. And some of the resistance genes have been applied to wheat production. In recent years, synthetic wheat lines were widely used to improve wheat quality, yield, and other important agronomic traits in many places all over the world, such as CIMMYT, the United States, Australia, China, which proved that synthetic wheat have the remarkable application value in the quality and yield of wheat breeding programs (Blanco et al. 2000; Calderiin et al. 2003; Pestsova et al. 2006; Liao et al. 2008; Li et al, 2011). It is said that "synthetic wheat offers hope to the world" (Coghlan 1991).

Though euploidy was the case in natural hexaploidy wheat, newly synthesized allohexaploid wheat was associated with widespread and persistent whole-chromosome aneuploidy and showed no significant differences of fitness between euploid and aneuploid at least under laboratory conditions. Zhang et al. (2013) showed that the structure mutations were rarely detected in new synthetic hexaploid wheat. However, chromosome number variations frequently happened companying with allopolyploidization. Sometimes, a "hidden" aneuploid carrying the same chromosome number as euploids but an aneuploidy compensation could be identified. It was reported (Bian et al. 2020) that the tolerant ones with increased euploidy frequency were able to be selected in early generations from the synthetic wheat which survived from the simulant of allohexaploid wheat conditions. Therefore, a certain frequency of cytological stable euploids could be obtained.

In the present study, we identified the karyotypes of inbred progenies of S8-S9 individual plants in the genetic background of synthetic hexaploid wheat NA0928 with the known chromosome constitutions and agronomic characters by cytological and fluorescence in situ hybridization (FISH) methods. We look forward to select out the disease resistant euploid stiains and provide more abundant genetic resources for wheat genetic breeding.

\section{Materials And Methods}

\section{Plant materials}

T. turgidum L. ssp. Dicoccum accession MY3478 $(2 n=4 x=28, B B A A)$, and Ae. tauschii Coss. $(2 n=2 x=$ 14, DD) accession SY41 were two parents. Synthesized hexaploid wheat population NA0928 was obtained by selfing the MY3478/SY41 triploid $\mathrm{S}_{1}$ hybrid plants. Neither embryo rescue nor hormone treatment was applied on the S1seeds. The S1 plants were self-pollinated to produce S2, S3, and to S8, S9 generations. By repeatedly selfing, S8-S9 plants carrying different chromosome numbers were preserved to form separate lines, in the field of College of Agronomy, Northwest A\&F University, located at the Yangling city of Shaanxi province, China. Hui Xianhong $(\mathrm{HXH})$ was the susceptible control of the stripe rust resistance evaluation at adult stages. Triticum urartu Thum. accession XM943 $(2 n=2 x=14$, AA), Ae. Speltoides accession SY183 $(2 n=2 x=14, \mathrm{BB}), \mathrm{MY} 3478$ and SY41 were provided by Dr Lihui Li from the Institute of Crop Science, Chinese Academy of Agricultural Sciences. 
The morphological traits of S8-S9 line NA0928, and its parents MY3478 and SY41, were assessed at the physiological maturity stage in 2016 and 2017, in the field. Each strain was planted 1 row, governor $1 \mathrm{~m}$, line spacing $0.1 \mathrm{~m}$, and plant height, spike length, spike grain number and other properties of each plant were reviewed before harvest.

The stripe rust resistance test was conducted at adult stages, respectively. A mixture of Pst races CYR32, CYR33 and CYR34 was used. When the susceptible control HXH was fully infected, MY3478,SY41 and each plant of S8 in NA0928 were investigated in the field. The reaction to the mixed Pst races was scored by infection type (IT) on a scale from 0-4 (Ma et al. 1995), as follows: 0 and 0; was assessed to be immune and nearly immune, 1 was regarded to be resistant, 2 was considered to be moderately resistant, 3 and 4 was recorded to be susceptible.

\section{Cytogenetics observation}

S8 generation seeds are harvested, select 5 seeds in each individual to observe the chromosome number. Cytogenetics observation of mitosis in root tip cells were performed as previously described by Wang et al. (2016), including indoor germination, taking root, and to observe the chromosome number.

In the field of S9 generation, the last generation plants containing 42 chromosomes were selected at the appropriate stage of development. Then these young inflorescences were immediately fixed in 6:3:1 ethanol-chloroform-acetic acid mixture. The subsequent procedures were as depicted (Wang et al. 2016).

The root tip cells (RTCs) and pollen mother cells (PMCs) with complete chromosome numbers of NA0928 in S8-S9 generation were analyzed and photographed with an Olympus BX-43 microscope (Japan) with a DP80 camera.

\section{FISH and multicolor-GISH}

Fluorescence in situ hybridization (FISH) was completed using synthetic oligonucleotide probes as described by Tang et al. (2014) and Zhao et al. (2016). Probes Oligo-pSc119.2 (green) and Oligo-pTa535 (red) were synthesized and labelled with FAM or TAMRA by Shanghai Invitrogen Biotechnology Co. Ltd. were used for FISH as described by Tang et al. (2014).

For the multicolor-GISH (mc-GISH) analysis, Triticum urartu Thum. DNA was labelled with Texas Red-5dUTP (Invitrogen) and Ae. tauschii Coss. DNA was labeled with Texas Green-5-dCTP (Invitrogen) (2014). Ae. Speltoides DNA was blocker. Chromosomes were counterstained with 4,6-diamidino-2-phenylindole (DAPI). Fluorescent signals were scanned and photographed with an Olympus BX53 microscope equipped with a Photometrics SenSys CCD DP80 camera (Japan). (Wang et al. 2016).

\section{Results}


Agronomic and stripe rust characters of new synthetic wheat NA0928 in S8 generation

S8-generation of NA0928 had 24 traits, and 124 plants were investigated in the field. The field statistical results were shown in table 1 and table 2. Agronomic character analysis of new synthetic wheat NA0928 in S8 generation showed that MY3478 was of high plant height with average $125 \mathrm{~cm}$, belonging to high stem. While the paternal plants were generally low, with abundant effective tillers up to 50 , and high resistance to stripe rust. Compared with the parents, the plant height of synthetic wheat NA0928 was between them, which were similar to the parental wheat. The effective tiller number capacity showed diversification. There were abundant genetic variations in agronomic traits between each strain. The effective tiller number $(55.3 \%)>$ spike length $(15.3 \%)>$ number of spikelets $(13.9 \%)>$ plant height $(8.7 \%)$. Among them, the highest coefficient of variation was the number of effective tillers, which reached $55.3 \%$. Stripe rust-resistant strains were generally higher than susceptible strains in agronomic traits. Especially the tillering number is the highest, generally more than 20. NA0928-2-1-10-4-1-1-1 and NA0928-2-1-10-4-13-9 had ten strains, Sixty-three plants, and spike lengths more than $15 \mathrm{~cm}$, number of spikelets has 2023 , effective tiller number was 20.6-30.7. These excellent agronomic traits have good utilization value in breeding.

The chromosome number of the S9 generations in NA0928

The root tip chromosome count results of 600 seeds showed that there were various variations in the somatic cell configurations of different synthetic S9 generations in NA0928. The chromosomes number varied as $36-44$, among which euploid accounted for $51.7 \%$, and aneuploid for $48.3 \%$. Removing the plants containing 42 chromosomes, the aneuploids with chromosome number ranging from 36 to 44 accounted for $0.3 \%, 1.0 \%, 2.0 \%, 2.7 \%, 6.6 \%, 26.0 \%, 8.7 \%$ and $1.0 \%$, respectively.

The number of chromosomes in different individual strains of the same strain was different. There were 126 seeds observed in strain NA0928-1-2-2-3-5-2-1 of S9 generations, two seeds have 36 chromosomes, five seeds have 37 chromosomes, nine seeds have 38 chromosomes, six seeds have 39 chromosomes, 10 seeds have 40 chromosomes, 18 seeds have 41 chromosomes, 70 seeds have 42 chromosomes, four seeds have 43 chromosomes, two seeds have 44 chromosomes, the euploid and aneuploid accounted for $55.6 \%$ and $44.4 \%$ respectively. In the line of NA0928-2-1-9-1-2-2-2-2, two seeds had 38 chromosomes, six seeds have 42 chromosomes, and one seed has 43 chromosomes, the euploid and aneuploid accounted for $66.67 \%$ and $33.33 \%$ respectively. In the line NA0928-1-2-2-3-5-2-1-4, 30 seeds have 42 chromosomes, no aneuploidy was observed. In the line NA0928-2-1-10-4-1-1-1-3 and NA0928-2-1-10-4-1-3-9-9, no aneuploidy was observed.

S9 generation of NA0928 FISH results

Five seeds per lines of $\mathrm{S} 9$ generation were selected randomly for FISH analysis. The results showed that nearly half of the individuals containing 42 chromosomes, and the chromosome constitution was consistent with two parents MY3478 (Fig. 1b1, 1b2) and SY41 (Fig. 1a). Oligo probes pSc119.2 and pTa535 can be used to distinguish the synthetic wheat Chromosomes. There were three types of variation 
with the same 42 chromosome, 1)All chromosomes have the same FISH pattern which were consistent with the two parents (Fig. 1a, 1b1, 1b2, 1c1, 1c2). NA0928-1-2-2-3-5-2-1, NA0928-2-1-9-1-2-2-2-1, NA09282-1-10-2-1-3-1-1, per plant carrying 42 chromosomes belonged to this type. 2) Several variations were clearly detected on some of the 42 chromosomes. The pSc119.2 signals (green) at the end of chromosome $2 \mathrm{~A}, 2 \mathrm{~B}$ and $5 \mathrm{~A}$ were lost while additional green signals were observed on the long arms of chromosome 4A (Fig. 1d). Each plant of NA0928-2-1-10-4-1-1-1 containing 42 chromosomes belonged to this type. $3 \square$ Apart from the chromosomal structure variations revealed in the second type, an additional strong green signal was identified at the end of chromosome $1 \mathrm{~A}$ short arm (Fig. 1C). Each plant of NA0928-2-1-10-4-1-3-9containing 42 chromosomes belonged to the third type.

The chromosome configuration types of aneuploids were abundant. Based on the same chromosome number, various chromosome configuration types were identified clearly. Four types were characterized when the aneuploids carrying 40 chromosomes. 1) Missing one chromosome 2B and 1D (Fig. 2a). 2) Missing one chromosome 1D and 5D (Fig. 2b). 3) Missing one chromosomes 4A and 5D (Fig. 2C). 4) Missing one chromosome 7A and 1D (Fig. 2d). While the aneuploids containing 41 chromosomes, a missing chromosome of 4B (Fig. 2e), 5B (Fig. 2f), 3A (Fig. 2g) and 7A (Fig. 2h) was identified in the different individuals, respectively. Only the chromosome $6 \mathrm{~B}$ was added to the aneuploids containing 42 chromosomes (Fig. 2h).

Combined the stripe rust resistance with FISH analysis results, something interesting was detected. The euploids or aneuploids carrying the same chromosome configuration as the parents were seriously susceptible to stripe rust. However, if there is any variation in chromosome configuration, the corresponding individual plant is highly resistant to stripe rust. That is to say, NA0928-2-1-10-4-1-1-1 and NA0928-2-1-10-4-1-3-9,all their offspring individual plant is highly resistant to stripe rust.

Cytological identification of S9 generation of NA0928 pollen mother cell in metaphase of meiosis

According to the FISH results, the plants carrying 42 chromosomes with normal configuration were selected to further analysis pollen mother cell at metaphase of meiosis. About 50 pollen mother cells were observed for each strain. The observation results were as follows: The $\mathrm{PMCl}$ chromosome configurations of the 2 lines (NA0928-2-1-9-1-2-2-2-1 and NA0928-2-1-10-4-1-1-1-3) in S9 generation showed normal expression in their pollen mother cells $(2 n=21 I I)$, and no monoploid appeared (Fig. $3 f$, $3 g$ ), Mc-GISH results showed that the chromosome composition of NA0928-2-1-9-1-2-2-2-1 and NA09282-1-10-4-1-1-1-3 were 14A + 14B + 14D (Fig. 3h, 3i ). These results suggest that NA0928-2-1-9-1-2-2-2-1 and NA0928-2-1-10-4-1-1-1-3 were basically stable. NA0928-2-1-9-1-2-2-2-1 was seriously susceptible to wheat stripe rust. On the contrary, NA0928-2-1-10-4-1-1-1-3 was highly resistant to stripe rust (Fig. 3e), and their grains were also significantly bigger whose thousand seed weight was more than $60 \mathrm{~g}$ (Fig. 3b, 3c). Hence, NA0928-2-1-10-4-1-1-1-3 was able to be utilized as a potential germplasm material for wheat breeding.

\section{Discussion}


Because of natural selection and artificial factors, numerous valuable genes with biological and nonbiological agronomic traits have been lost gradually, such as disease resistance, tolerance to stresses and variety of processing properties and so on. As a result, now genetic background of common wheat is more and more narrow, especially for quality and resistance traits (Liu et al. 2016). Therefore, studies of new synthetic hexaploid wheat have been more and more extensive and in-depth. In recent years, new synthetic hexaploid wheat has been widely used for yield increase and quality improvement of wheat (Calderiin et al. 2003; Pestsova et al. 2006). CIMMYT and Australian scientists found that the synthetic wheat were $8 \%$ and $30 \%$ of potential yield improvement compared with local varieties under the same condition of irrigation and irrigation (Dreccer et al. 2007; Del et al. 2003). Ogbonnaya (2007) found that more than $80 \%$ of the synthetic derivatives of wheat were outstanding in terms of thousand seed weight, yield and other agronomic traits compared to its recurrent parent, performing better. Li (2011) found that one high-yield potential locus Barc1183 derived from the synthetic hexaploid wheat was detected in Chuanmai 42. This locus had positive effects on increasing tiller number per plant, number of effective spikes, grain number per square meter, harvest index, and grain production rate, and the average yield was increased by $8.92 \%$ compared with Chuannong 16 in the six growing environments. According to previous studies, several stripe rust genes contained in synthetic hexaploidy wheat have been reported. Yr48 was derived from wheat genotype PI 610750, synthetic spring wheat with pedigree Croc1/Ae. tauschii (Synthetic 205)//Kauz, in the terms of disease severity, the main effect of Yr48 accounted for $10 \%$ of the observed variation in the field and was associated with an average reduction in disease severity of 63\% (Chen et al. 2017; Lowe et al. 2011). Another resistance gene YrC142 confers ASR to stripe rust and was originated from synthetic wheat Cl142 from cross Garza/ Boy// Ae. squarrosa 271. YrC142 showed resistance to six Chinese Pst races. (Chen et al. 2017; Wang et al. 2009). In the present study, some of offspring strains had prominent characteristics compared with their parents, such as more effective tillers, longer spike, more spikelets, and resistant to stripe rust. Especially, the higher thousand seed weight of NA0928-2-1-9-1-2-2-2-1 and NA0928-2-1-10-4-1-1-1-3 were even more than $55 \mathrm{~g}$ (Fig. 3). These two remarkable lines could be further utilized in wheat breeding programs.

The stability appears to break down when the number of chromosomes increase or decrease exceeds one, which may directly result in severe aneuploid states, such as nullisomy, monosomy, trisomy and tetrasomy. It showed that aneuploids generally happened and rarely recovered among the progeny of newly synthesized hexaploid wheat (Zhang et al. 2013; Zeng et al. 2020). In previous studies, wheat of aneuploids was widely used for gene location, molecular marker development and genetic analysis (Endo et al. 1996; Klindworth et al. 2007; Zhang et al. 2020; Pshenichnikova et al. 2020). China spring monomer and durum wheat Langdon chromosome substitution lines are commonly used for gene mapping as tool materials (Sears 1953; Shimelis et al. 2011; Wang et al. 2020). Based on the durum wheat-Langdon substitution lines and Abbondanza monosomic system, the crossability related genes were located in chromosome 1A, 6A and 7A by Liu (1999). Here, several aneuploidy individuals were identified through cytology identification, such as the lack of chromosome 2B, 4B, 5B, 6B, 1D, 5D, 4A, 7A, etc. Based on the aneuploids, the stable genetic tool materials are able to be created by after years of offspring directional selections, which could very important tool materials used for genetic researches. 
Due to polyploidization companying with the whole genome reorganization, most newly synthesized allohexaploid wheat had to suffer from cytological instability. Most of these rearrangements may be caused by chromosome pairing anomalies, which causes frequent homoeologous recombination (Marais et al. 2003). As a result, several cross exchanges and gene transformation happened and finally lead to the loss of part of the homoeologous genes. Hence, the variations of chromosome number and chromosomal structure detected in this study could be reasonably explained (Gaeta et al. 2010)

Previous studies showed that the chromosome configuration of early generations in new synthesis hexaploidy wheats were frequently unstable (Cmai 2000; Zhao et al. 2011). In this study, the FISH patterns of NA0928 in S9 generation showed several chromosomal structure variations compared with their parents MY3478 and SY41. It was showed that the pSc119.2 signals (green) at the end of chromosome 2A, 2B and 5A were lost while additional green signals were observed on the long arms of chromosome 4A, and chromosome 1A short arm, respectively. Therefore, although the chromosome number of synthetic wheat lines was close to or as the same as a common wheat, the chromosome configuration had many differences. The chromosomal structure variations were almost detected in A and $\mathrm{B}$ genomes, and no changes were observed in D genome by FISH analysis. Which was consistent with Pont and Liu etc (Pont et al. 2013; Liu et al. 2015). It was reported that the two subgenomes of natural tetraploid and the three subgenomes of hexaploid wheat are distinctively different in propensities to undergo evolutionary genomic changes, with the B subgenome being more labile, the A subgenome is more stable while the $D$ subgenome is the most stable. This suggests that repeat sequences missing or restructuring during the process of allopolyploidization may lead to a novel phenotype emergence. It could also explain the excellent resistance to stripe rust carried by NA0928-2-1-10-4-1-1-1-1 and NA09282-1-10-4-1-3-9-1 with a worthy of chromosomal structure variations. The offspring of new synthesis hexaploid wheat observed no chromosomes variations compared with their parents, the gene(s) were speculated to be silence. On the contrary, the offspring was resistance, which meant that the balance between the parental chromosomes was broken, and the resistance was performed. Much more work should be done for a further research.

\section{Declarations}

Author contributions YJ Wang and WQ Ji conceived the project. YJ Wang created materials. YJ Wang and SW Wang conducted the experiments and analyzed the data. XJ Jia conducted the experiments. ZR Tian, $\mathrm{CY}$ Wang and $\mathrm{H}$ Zhang helped in data processing. YF Wang, XL Liu, JX Zhao and PC Deng assisted in field works. YJ Wang wrote the manuscript. WQ Ji and SW Wang revised the manuscript. All authors read and approved the manuscript.

\section{Funding information}

This work was supported by the National Key Research and Development Program of China (grant No. 2016YFD0102000), and Crop Germplasm Resources Protection (No. 2019NWB036-02-1).

\section{Compliance with ethical standards}


Conflict of interest The authors declare that they have no competing interests.

Open Access This article is licensed under a Creative Commons Attribution 4.0 International License, which permits use, sharing, adaptation, distribution and reproduction in any medium or format, as long as you give appropriate credit to the original author(s) and the source, provide a link to the Creative Commons licence, and indicate if changes were made. The images or other third party material in this article are included in the article's Creative Commons licence, unless indicated otherwise in a credit line to the material. If material is not included in the article's Creative Commons licence and your intended use is not permitted by statutory regulation or exceeds the permitted use, you will need to obtain permission directly from the copyright holder. To view a copy of this licence, visit http://creativecommons.org/licenses/by/4.0/.

\section{References}

Assefa S, Fehrmann H (2004) Evaluation of Aegilops tauschii Coss for resistance to wheat stem rust and inheritance of resistance genes in hexaploid wheat. Genet Resources and Crop evolution 51:663-669

Bian Y, Yang CW, Ou XF, Zhang ZB, Wang B, Ma WW, Gong L, Zhang HK, Liu B (2020) Meiotic chromosome stability of a newly formed allohexaploid wheat is facilitated by selection under abiotic stress as a spandrel. New phytologist 220:262-277

Blanco IA, Rajararm S, Kronstad WE (2000) Physiological performance of synthetic hexaploid wheatderived populations. Crop Science 40: 1257-1263

Brenchley R, Spannagl M, Pfeifer M, Barker G, D’Amore R, Allen AM, McKenzie N, Kramer M, Kerhornou A, Bolser D, Kay S, Waite D, Trick M, Bancroft I, Gu Y, Huo NX, Luo MC, Sehgal SK, Gill B, Kianian SF, Anderson O, Kersey P, Dvorak J, Mccombie WR, Hall A, Mayer KFX, Edwards KJ, Bevan M, Hall N (2012) Analysis of the bread wheat genome using whole-genome shotgun sequencing. Nature 491:705-710

Calderiin DF, Ortiz-Monasterio I (2003) Are syntetic hexaploids a means of inereasing grain element concentrations in wheat. Euphytica 134:169-178

Chen XM, Kang ZS (2017) Stripe rust. Library of Congress Control Number: 2017943111

Coghlan A (1991) Sythetic wheat offers hope to the world. New Scientist 25-38

Comai L (2000) Genetic and epigenetic interactions in allopolyploid plants. Plant Mol Biol 43:387-99

Del BA, Rajaram S, Kronstad WE (2001) Agronomic potential of synthetic hexaploid wheat derived populations. Crop Sci 41:670-676

Dreccer MF, Borgognone MG, Ogbonnaya FC, Trethowan RM, Winter B (2007) CIMMYT selected derived synthetic bread wheat for rainfed environments: yield evaluation in Mexico and Australia Field. Crops Res 100:218-228 
Endo TR, Gill BS (1996) The deletion stocks of common wheat. Journal of Heredity 87:295-307

Fedak G, Chen Q, Conner RL, Laroche A, Petroski R, Armstrong KW (2000) Characterization of wheatThinopyrum partial amphiploids by meiotic analysis and genomic in situ hybridization. Genome 43:712719

Gaeta RT, Chris Pires J (2010) Homoeologous recombination in allopolyploids: the polyploid ratchet. The New phytologist 186: 18-28

He HG, Liu RK, Ma PT, Du HN, Zhang HH, Wu QH, Yang LJ, Gong SJ, Liu TL, Huo NX, Gu YQ, Zhu SY (2020) Characterization of Pm68, a new powdery mildew resistance gene on chromosome 2BS of Greek durum wheat TRI 1796. Theor Appl Genet 9: https://doi.org/10.1007/s00122-020-03681-2

Klindworth DL, Miller JD, Jin Y, Xu SS (2007) Chromosomal locations of genes for stem rust resistance in monogenic lines derived from tetraploid wheat accession ST464. Crop Science 47:1441-1450

Lage J, Skovmand B, Andersen SB (2000) Field evaluation of emmer wheat derived synthetic hexaploid wheats for resistant to the Russian wheat aphid (Homoptera: Aphididae). J Econ Entomol 97:1065-1070

Lage J, Skovmand B, Andersen SB (2003) Expression and suppression of resistance to Greenbug (Homoptera: Aphididae) in synthetic hexaploid wheats derived from Triticum dicoccum $\square$ Aegilops tauschii crosses. J. Econ Entomol 96:202-206

Lange W, Jochemsen G (1992a) Use of the gene pools of Triticum turgidum ssp.dicocoides and Aegilops squarrosa for the breeding of common wheat (T.aestivum) through chromosome-double hybrids I. Two strategies for the production of the amphiploids. Euphytica 59:213-220

Lange W, Jochemsen G (1992b) Use of the gene pools of Triticum turgidum ssp.dicocoides and Aegilops squarrosa for the breeding of common wheat (T.aestivum) through chromosome-double hybrids. II. Morphology and meiosis of the amphiploids. Euphytica 59:213-220

Li J, Wei HT, Hu XR, Li CS, Tang YL, Liu DC, Yang WY (2011) Identification of a high-yield introgression locus from synthetic hexaploid wheat in Chuanmai 42. Aata Agronomica Sinica 37:255-262

Liao XZ, Wang J, Zhou RH, Ren ZL, Jia JZ (2008) Mining favorable alleles of QTLs conferring 1000-Grain Weight from synthetic wheat. Aata Agronomica Sinica 34:1877-1884

Liu C, Yang XJ, Zhang HK, Wang XT, Zhang ZB, Bian Y, Zhu B, Dong YZ, Liu B (2015) Genetic and epigenetic modifications to the BBAA component of common wheat during its evolutionary history at the hexaploid level. Plant Mol Biol 88:53-64

Liu XL, Yang XF, Wang CY, Wang YJ, Zhang H, Ji WQ (2012) Molecular mapping of resistance gene to English grain aphid (Sitobion avenae F.) in Triticum durum wheat line C273. Theor Appl Genet 124:287293 
Liu DC, Yen C, Yang JL, Zheng YL, Lan XJ (1999) The chromosomal distribution of crossability genes in tetraploid wheat Triticum turgidum L. cv. Ailanmai native to Sichuan. China, Euphytica 108:79-82

Liu DC, Hao M, Li AL, Zhang LQ, Zheng YL, Mao L (2016) Allopolyploidy and interspecific hybridization for wheat improvement. In Polyploidy and hybridization for crop improvement. CRC Press: 27-52

Lowe I, Jankuloski L, Chao SM, Chen XM, See D, Dubcovsky J (2011) Mapping and validation of QTL which confer partial resistance to broadly virulent post-2000 North American races of stripe rust in hexaploid wheat. Theor Appl Genet 123:143-57

Ma H, Singly RP, Mujeeb-Kazi A (1995) Suppression/expression of resistance to stripe rust in synthetic hexaploid wheat (Triticum turgidum X T. tauschii). Euphytica 83:87-93

Marais G, Charlesworth B (2003) Genome evolution: recombination speeds up adaptive evolution. Current Biology 13:68-70

Miranda LM, Murphy JP, Marshall D, Cowger C, Leath S (2007) Chromosomal location of Pm35, a novel Aegilops tauschii derived powdery mildew resistance gene introgressed into common wheat (Triticum aestivum L.). Theor Appl Genet 114:1451-1456

Mohler V, Bauer C, Schweizer G, Kempf H, Hartl L (2013) Pm50: a new powdery mildew resistance gene in common wheat derived from cultivated emmer. J Appl Genet 54:259-263

Ogbonnaya FC, Ye GY, Trethowan R, Dreceer F, Lush D, Shepperd J, Ginkel Mvan (2007) Yield of synthetic backcross-derived lines in rainfed environments of Australia. Euphytica 3:321-336

Pestsova E, Borner A, Roder MS (2006) Development and QTL assessment of Triticum aestivum Aegilops tauschii introgression lines. Theor Appl Genet 112:634-647

Pont C, Murat F, Guizard S, Flores R, Foucrier S, Bidet Y, Quraishi UM, Alaux M, Doležel J, Fahima T (2013) Wheat syntenome unveils new evidences of contrasted evolutionary plasticity between paleo-and neoduplicated subgenomes. Plant J 76:1030-1044

Prasad M, Varshney RK, Roy JK, Balyan HS, Gupta PK (2000) The use of microsatellites for detecting DNA polymorphism genotype identification and genetic diversity in wheat. Theor Appl Genet 100:584-592

Pshenichnikova TA, Smirnova OG, Simonov AV, Shchukina LV, Morozova EV, Lohwasser U, Börner A (2020) The relationship between root system development and vernalization under contrasting irrigation in bread wheat lines with the introgressions from a synthetic hexaploid. Plant Growth Regulation 92:583595

Sears ER (1953) Nullisomic analysis in common wheat. The American Naturalist 87:245-252 
Shimelis H, Spies JJ (2011) Aneuploids of wheat and chromosomal localization of genes. African Journal of Biotchnology 10:5545-5551

Simo'n MR, Worland AJ, Cordo CA, Struik PC (2001) Chromosomal location of resistance to Septoria tritici in seedlings of a synthetic hexaploid wheat, Triticum spelta and two cultivars of Triricum aestivum. Euphytiea 119:151-155

Singh RP, Nelson JC, Sorrells ME (2000) Mapping Yr28 and other genes for resistance to stripe rust in wheat. Crop Science 40:1148-1155

Tang ZX, Yang ZJ, Fu SL (2014) Oligonucleotides replacing the roles of repetitive sequences pAs1, pSc119.2, pTa-535, pTa71, CCS1, and pAWRC.1 for FISH analysis. J Appl Genet 55:313-318

Wang LM, Zhang ZY, Liu HJ, He MZ, Liu HX, Veisz O, Xin ZY (2009) Identification, gene postulation and molecular tagging of a stripe rust resistance gene in synthetic wheat $\mathrm{Cl} 142$. Cereal Res Commun 37: 209215

Wang YJ, Quan W, Peng NN, Wang CY, Yang XF, Liu XL, Zhang H, Chen CC, Ji WQ (2016) Molecular cytogenetic identification of a wheat-Aegilops geniculata Roth $7 \mathrm{Mg}$ disomic addition line with powdery mildew resist ance. Mol Breeding 36:40

Wang YJ, Long DY, Wang YZ, Wang CY, Liu XL, Zhang H, Tian ZR, Chen CC, Ji WQ (2020) Characterization and evaluation of resistance to powdery mildew of wheat-Aegilops geniculata Roth $7 \mathrm{Mg}(7 \mathrm{~A})$ alien disomic substitution line W16998. Int J Mol Sci 21:1861

Wiersma AT, Pulman JA, Brown LK, Cowger C, Olson EL (2017) Identification of Pm58 from Aegilops tauschii . Theor Appl Genet 130:1123-1133

Xiang C, Feng JY, Wang MN, Chen XM, See DR, Wan AM, Wang T (2016) Molecular Mapping of Stripe Rust Resistance Gene Yr76 in Winter Club Wheat Cultivar Tyee. Phytopathology 106:1186-1193

Zeng DY, Guan JT, Luo JT, Zhao LB, Li YZ, Chen WS, Zhang LQ, Ning S Z, Yuan ZW, Li AL, Zheng YL, Mao L, Liu DC, Hao M (2020) A transcriptomic view of the ability of nascent hexaploid wheat to tolerate aneuploidy. BMC plant biology 20: 97

Zhang MY, Zhang W, Zhu XW, Sun Q, Yan CH, Xu S, Fiedler J, Cai XW (2020) Dissection and physical mapping of wheat chromosome $7 \mathrm{~B}$ by inducing meiotic recombination with its homoeologues in Aegilops speltoides and Thinopyrum elongatum. Theor Appl Genet 133:3455-3467

Zhang HK, Bian Y, Gou XW, Zhu B, Xu CM, Qi B, Li N, Rustgi S, Zhou H, Han FP, Jiang JM, Wettstein DV, Liu B (2013) Persistent whole-chromosome aneuploidy is generally associated with nascent allohexaploid wheat. Proceedings of the National Academy of Sciences 110:3447-3452 
Zhao LB, Ning SZ, Yu JJ, Hao M, Zhang LQ, Yuan ZW, Zheng YL, Liu D C (2016) Cytological identification of an Aegilops variabilis chromosome carrying stripe rust resistance in wheat. Breed Sci 66:522-529

Zhao N, Zhu B, Li MJ, Wang L, Xu LY, Zhang HK, Zheng SS, Bao Q, Han FP, Liu B (2011) Extensive and heritable epigenetic remodeling and genetic stability accompany allohexaploidization of wheat. Genetics 188: $499-510$

\section{Tables}

Due to technical limitations, table 1 and 2 is only available as a download in the Supplemental Files section.

\section{Figures}



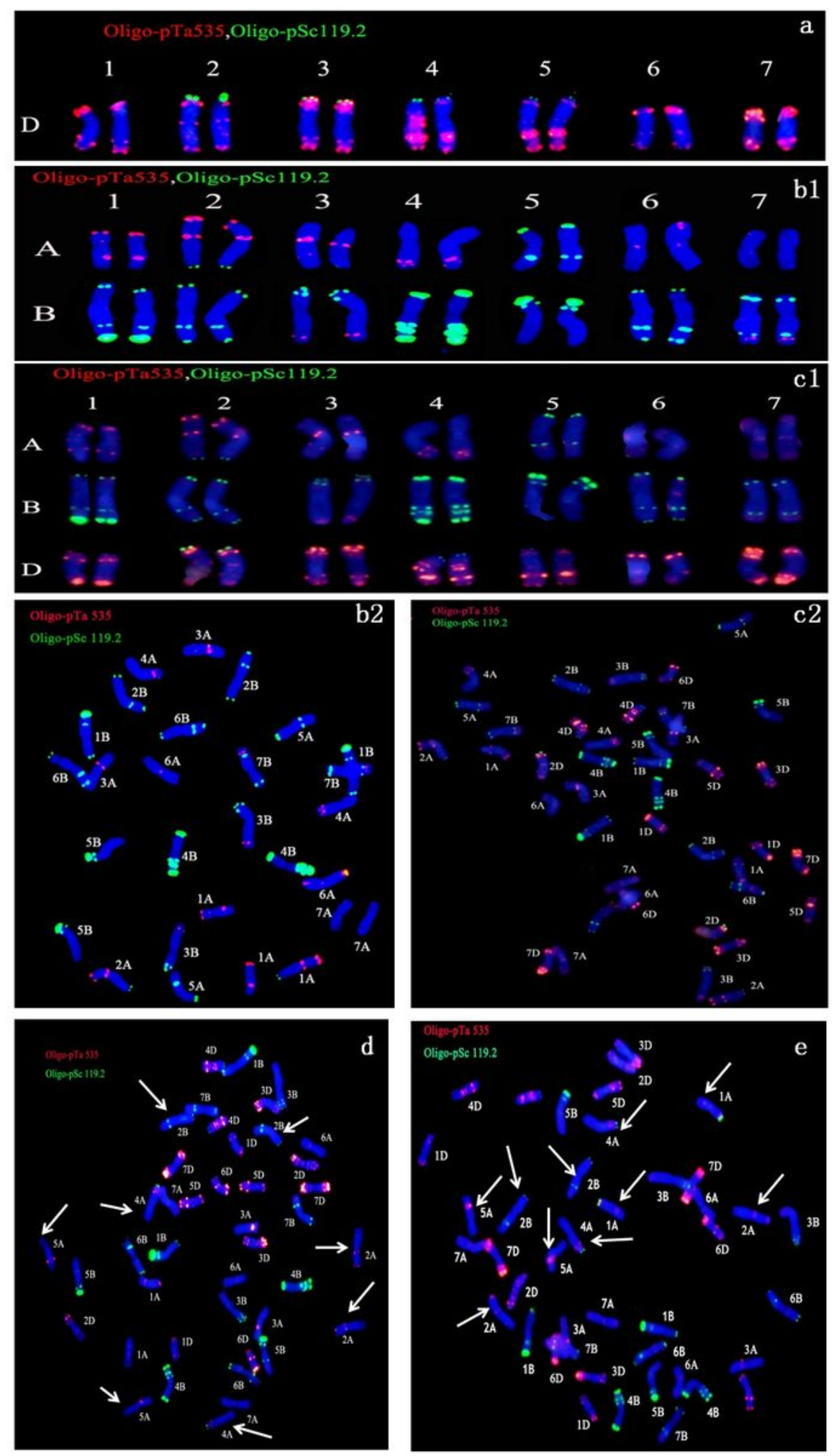

\section{Figure 1}

The euploid and parent configurations lines in S9 generation by FISH results. a: SY41; b1, b2: MY3478; $c 1, c 2: 2 n=42$ normal karyotype; $d, e: 2 n=42$ variation type. The whitearrows indicate 

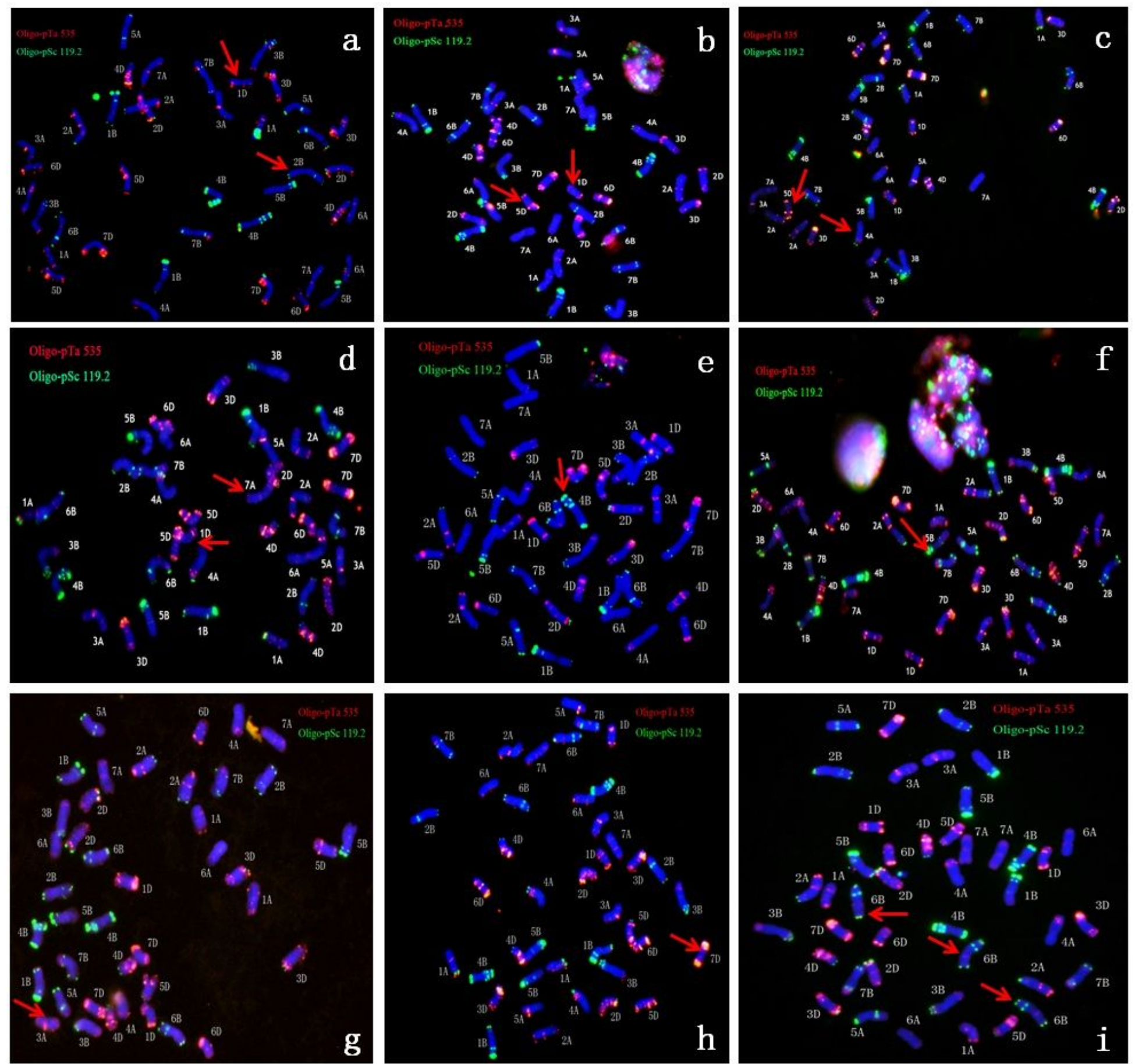

\section{Figure 2}

The aneuploidy configurations lines in S9 generation by FISH results. a-d:2n=40; e-h:2n=41; i:2n=43. The corresponding individual respectively are the following: NA0928-1-2-2-3-5-2-1-1, NA0928-2-1-10-4-1-3-9-1, NA0928-2-1-10-4-1-3-9-2, NA0928-2-1-10-4-1-3-9-5, NA0928-1-2-2-3-5-2-1-3, NA0928-2-1-9-1-2-2-2-3, NA0928-2-1-9-1-2-2-2-4, NA0928-2-1-10-2-1-3-1-4. Red arrow is missing or added chromosomes 

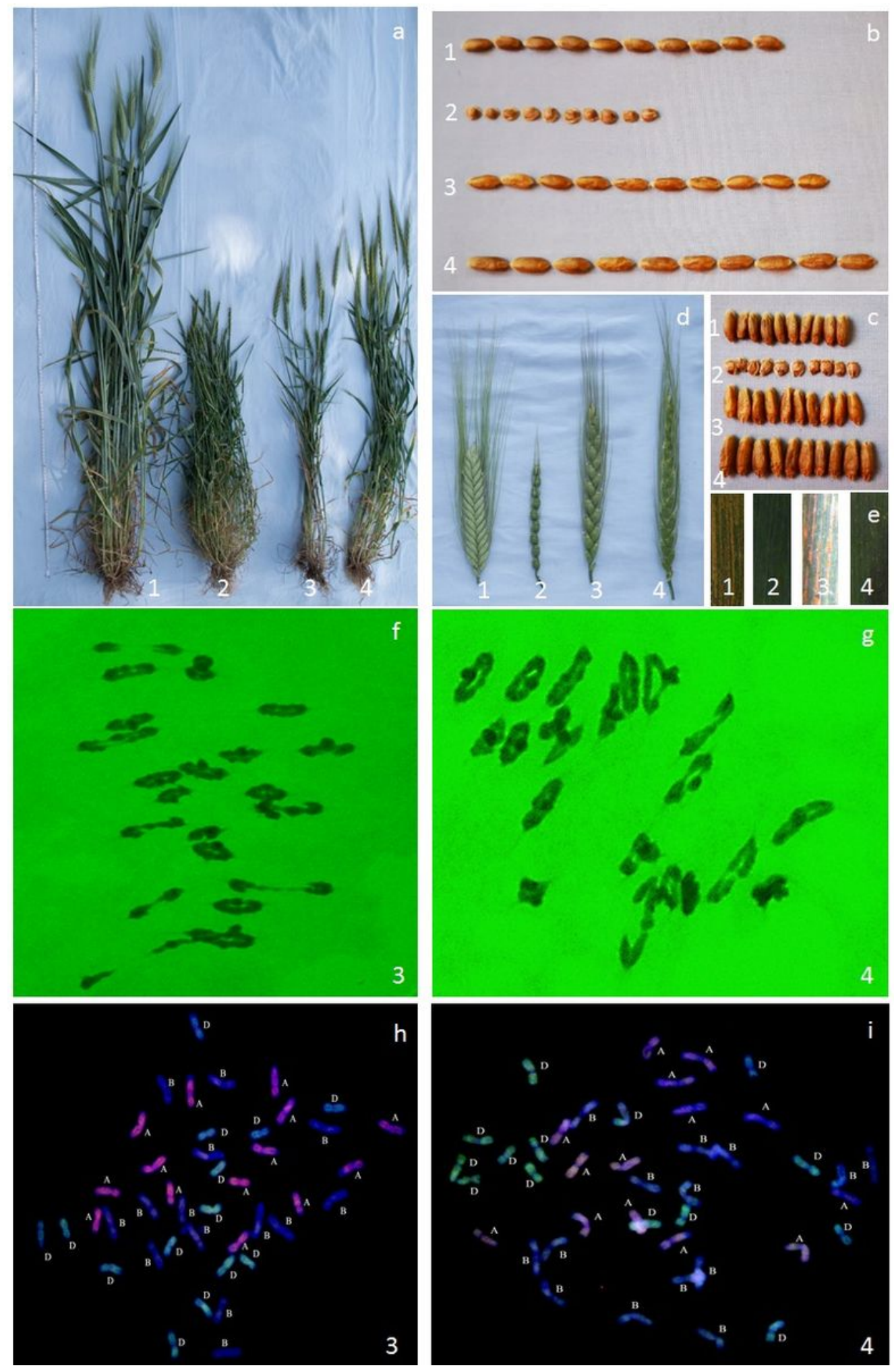

\section{Figure 3}

Morphological『configurations at meiotic metaphase and powdery mildew reactions of NA0928 in S9 generation. 1:CS; 2:SY159; 3:NA0928-2-1-9-1-2-2-2-1; 4:NA0928-2-1-10-4-1-1-1-3. a: Plants; b,c: Spikes; d: Kernel; e: symptoms in response to inoculation with Pst races CYR32, CYR33 and CYR34 at the adult stages; f-g: Configurations at meiotic metaphase; h-i: mc-GISH. Ae. tauschii Coss. genomic DNA (green) 
and Triticum urartu Thum. genomic DNA (red) were used as probes, Ae. Speltoides genomic DNA was blocker, chromosomes were counterstained with DAPI (blue).

\section{Supplementary Files}

This is a list of supplementary files associated with this preprint. Click to download.

- Table.pdf 